\title{
Pemaknaan Khalayak pada Iklan Animasi Gojek Versi Pevita Pearce dan Joe Taslim
}

\author{
Niluh Putu Krisna Utami ${ }^{1}$, Septia Winduwati ${ }^{*}$ \\ ${ }^{1}$ Fakultas Ilmu Komunikasi Universitas Tarumanagara, Jakarta \\ Email: niluh.915170068@stu.untar.ac.id \\ ${ }^{2}$ Fakultas Ilmu Komunikasi Universitas Tarumanagara, Jakarta* \\ Email:septiaw@fikom.untar.ac.id
}

Masuk tanggal : 15-12-2021, revisi tanggal : 06-01-2022, diterima untuk diterbitkan tanggal : 16-01-2022

\begin{abstract}
Gojek is an online service application that provides transportation, food, delivery services and provides digital wallet payment methods, namely Gopay. One of the ways Gojek introduced the Gopay service is by creating an advertisement to attract its target market because advertising is considered effective in conveying a message. Gojek animation advertisement is an advertisement that has its own uniqueness and appeal, because it is the first advertisement in Indonesia that applies animation techniques to advertisements. The focus of this research is to find out the reception or the meaning of the audience and to know the position of the audience in receiving the animated advertising message Gojek version of Pevita Pearce and Joe Taslim. The researcher used the theoretical basis of a qualitative approach with a case study research method and Stuart Hall's reception analysis. Researchers conducted interviews with 3 informants who watched Gojek's animated advertisements. The active role of the audience in interpreting messages can be seen in Stuart Hall's encoding-decoding model, there are 3 audience categories, namely dominant hegemony position, negotiation and opposition. The results showed that the audience reception who became the informants in this study were all dominated by the dominant hegemony position, namely the placement of the audience towards receiving messages in accordance with the meaning of the messages received without exception.
\end{abstract}

Keywords: ads, animation, Gojek, meaning

\begin{abstract}
Abstrak
Gojek adalah salah satu aplikasi layanan jasa online yang menyediakan layanan transportasi, makanan, pengiriman dan menyediakan layanan metode pembayaran dompet digital Gopay. Salah satu cara Gojek memperkenalkan layanan Gopay yaitu dengan cara membuat sebuah iklan untuk menarik target pasarnya karena iklan dianggap efektif dalam menyampaikan sebuah pesan. Iklan animasi Gojek merupakan iklan yang memiliki keunikan dan daya tarik tersendiri, karena merupakan iklan pertama di Indonesia yang mengaplikasikan teknik animasi kedalam iklan. Fokus penelitian ini adalah untuk mengetahui resepsi atau pemaknaan khalayak serta mengetahui posisi khalayak dalam penerimaan pesan iklan animasi Gojek versi Pevita Pearce dan Joe Taslim. Peneliti menggunakan landasan teori pendekatan kualitatif dengan metode penelitian studi kasus dan analisis resepsi dari Stuart Hall. Peneliti melakukan wawancara kepada 3 informan penonton iklan animasi Gojek. Peran aktif penonton dalam memaknai pesan dapat terlihat pada model encoding-decoding Stuart Hall, ada 3 kategori penonton yaitu posisi hagemoni dominan, negosiasi dan oposisi. Hasil penelitian menunjukkan bahwa resepsi khalayak yang menjadi informan dalam penelitian ini ketiganya didominasi oleh posisi hagemoni dominan yaitu penempatan khalayak terhadap penerimaan pesan sesuai dengan makna pesan yang diterima tanpa pengecualian.
\end{abstract}

Kata Kunci: animasi, iklan, Gojek, pemaknaan 


\section{Pendahuluan}

Iklan adalah sebuah media yang dapat digunakan oleh suatu perusahaan sebagai alat untuk, membujuk, memengaruhi dan memberikan informasi kepada konsumen tentang suatu produk atau jasa. Periklanan ini ditentukan juga oleh media. Media merupakan elemen paling terpenting di dalam sebuah iklan, karena meia yang tepat akan keberhasilan dari sebuah iklan di dunia periklanan.

Seiring perubahan teknologi komunikasi, media pun mengalami pergeseran. Kini media yang banyak menjadi pilihan adalah media digital untuk membantu komunikasi pemasaran, salah satunya adalah media sosial. Salah satu media sosial yang kini menjadi perhatian pengguna media digital adalah Youtube. YouTube merupakan media baru yang mudah diakses dan digunakan.

Tidak mengherankan jika media ini menajdi alternatif dalam beriklan. Sebagai media Iklan, YouTube dapat memberikan dukungan yang kuat kepada perusahaan untuk mempromosikan produk atau jasa, yang pada akhirnya dapat meningkatkan penjualan untuk mendapatkan keuntungan. Inilah alasan mengapa Gojek memilih Youtube sebagai media beriklan. Di ini Gojek mencoba untuk memanfaatkan Youtube untuk mengiklankan salah satau fitur andalannya, Gopay.

Gopay adalah salah satu alternatif media pembayaran non-tunai yang disediakan oleh Gojek. Melalui iklan animasi, Gopay diperkenalkan kepada target market. Dalam iklan ini dipaparkan bahwa Gopay dapat mempermudah pembelian Iklan Gojek di atas ditayangkan dalam bentuk animasi. Iklan animasi Gopay versi Pevita Pearce dan Joe Taslim yang ditayangkan di Youtube itu didesain sedemikian rupa sehingga terdapat banyak makna dapat disampaikan kepada khalayak.

Brown, sebagaimana dipaparkan Sobur (Mustafa dkk, 2015) mendefinisikan makna sebagai kecenderungan (disposisi) total untuk bereaksi terhadap suatu bentuk bahasa. Bahasa tersusun atas tanda-tanda. Littlejohn (Herawati dan Rosidah, 2015) menjelaskan suatu tanda menandakan sesuatu selain dirinya sendiri, dan makna adalah hubungan antara suatu objek atau ide dan suatu tanda.

Dengan demikian, penulis memahami bahwa tanda-tanda yang terdapat pada iklan memiliki makna. Tanda-tanda ini menggambarkan realitas. Dalam periklanan, tanda-tanda ini berupa efek visual (misalnya, adegan berbakat dan gambar grafis), audio (suara latar), dan kata-kata yang diucapkan dalam iklan (musik dan suara). Khalayak dalam resepsi khalayak adalah individu-individu dengan latar belakang yang berbeda, selain itu resepsi khalayak menganggap khalayak berperan aktif dalam menginterpretasikan pesan, setiap orang dianggap mempunyai makna yang berbedabeda dalam menyikapi pesan.

Penelitian ini dilakukan karena penulis melihat adanya keunikan dan ketertarikan terhadap iklan yang diluncurkan oleh Gojek di atas. Selain itu, iklan Gojek tersebut merupakan iklan pertama di Indonesia yang menggunakan teknik video dengan format teknologi CGI sehingga pengaplikasikan tersebut adalah hal yang baru pada sebuah iklan .CGI (Computer Generated Imagery) merupakan teknik pencitraan 3D yang dilakukan oleh komputer pada media tertentu.

Berdasarkan latar belakang di atas, maka rumusan masalah penelitian ini adalah bagaimana pemaknaan khalayak pada iklan animasi Gojek versi Pevita Pearce dan Joe Taslim. Tujuan yang ingin dicapai dalam penelitian ini adalah untuk mengetahui pemaknaan khalayak pada iklan animasi tersebut.

Kerangka pemikiran utama yang digunakan pada penelitian ini yaitu konsep resepsi khalayak menurut Stuart Hall yaitu mengenai teori Decoding-Encoding. Peran 
aktif audiens dalam memaknai teks dapat terlihat pada model encoding-decoding Stuart Hall, yaitu model yang menjelaskan bahwa sebuah pesan yang sama dapat dikirimkan atau diterjemahkan lebih dari satu cara. Model ini fokus pada ide bahwa audiens seringkali menginterpretasikan pesan media melalui cara-cara yang tidak dikehendaki oleh sumber pesan sehingga menimbulkan makna yang berbeda. Akibatnya ideologi yang berlawanan akan muncul di masyarakat.

Pesan yang telah dikirimkan akan menimbulkan berbagai macam efek kepada audiens. Stuart Hall (Morissan, 2014:4) mengidentifikasi tiga kategorisasi audiens yang telah mengalami proses encodeldecode sebuah pesan : Posisi Hegemoni Dominan (dominant hegemonic position), yaitu posisi dimana media menyampaikan pesan, khalayak menerimanya. Apa yang disampaikan media secara kebetulan juga disukai oleh khalayak. Posisi Negosiasi (negotiated posisition), dimana khalayak bersedia menerima ideologi dominan yang bersifat umum, namun mereka akan melakukan beberapa pengecualian dalam penerapannya. Posisi Oposisi (oppositional posisition), terjadi ketika khalayak audiens yang kritis mengganti atau mengubah pesan atau kode yang disampaikan media dengan pesan atau kode alternatif.

Analisis tersebut mengasumsikan bahwa tidak ada efek tanpa makna. Dalam hal ini khalayak akan memaknai kembali pesan yang disampaikan oleh media, dan pemaknaan khalayak akan menghasilkan berbagai efek, dan efek tersebut merupakan tahap akhir dari penelitian ini.

\section{Metode Penelitian}

Peneliti menggunakan pendekatan kualitatif dengan metode penelitian studi kasus yaitu meneliti secara mendalam mengenai Pemaknaan Khalayak Pada Iklan Animasi Gojek Versi Pevita Pearce dan Joe Taslim. Teknik pengumpulan data yang digunakan oleh peneliti yaitu mengunakan teknik wawancara, wawancara dilakukan kepada informan agar mendapatkan informasi tentang pendapat dan resepsi khalayak terhadap iklan animasi Gojek.

Penelitian ini juga didukung dengan studi dokumentasi dan studi pustaka agar penelitian mendapatkan hasil yang maksimal. Teknik analisis data yang digunakan peneliti adalah dengan melalukan pengumpulan data, reduksi data, penyajian data, dan kesimpulan (verifikasi). Serta teknik keabsahan data menggunakan teknik triangulasi sumber yaitu dengan cara pengecekan dan membandingkan informasi atau data dari hasil wawancara.

\section{Hasil Temuan dan Diskusi}

Penelitian ini membahas pemaknaan khalayak terhadap iklan animasi Gojek versi Pevita Pearce dan Joe Taslim. Peneliti memilih 3 informan yang merupakan khalayak aktif karena informan dalam penelitian ini adalah pengguna layanan dan aplikasi Gojek lebih dari 2 tahun dan informan sudah menonton video iklan animasi Gojek, serta informan adalah penggunan layanan dompet digital Gopay.

Penyataan ini dikaitkan yaitu asumsi dasar analisis resepsi adalah konsep yakni khalayak aktif (Ida, 2014 :4). Khalayak aktif adalah khalayak yang mempunyai kemampuan untuk memproduksi dan mereproduksi makna yang ada di dalam teks yang dikonsumsinya.

Memproduksi dan mereproduksi artinya informan memahami dan menerima makna (pesan) yang disampaikan oleh iklan animasi Gojek versi Pevita Pearce dan Joe 
Taslim serta informan merespon dan memberikan pendapat mereka mengenai makna yang mereka pahami dalam iklan animasi Gojek tersebut. Hal tersebut dapat diartikan bahwa informan yang aktif dapat membangun dan menginterprestasikan makna atas apa yang dilihat, dibaca dan didengar sesuai dengan konteks budaya.

Dalam pemaknaan, ada proses Encoding dan Decoding, proses Encoding dalam penelitian ini adalah melalui bagaimana kode-kode tersebut disampaikan. Makna dan pesan yang disampaikan iklan animasi Gojek versi Pevita Pearce dan Joe Taslim ini terlihat dari cara Pevita membeli senjata menggunakan Gopay, dan saat Pevita melakukan transaksi untuk berlangganan YouTube premium di GooglePlay.

Kegiatan ini ditampilkan dan juga dikemas sedemikian rupa sehingga mampu menarik penonton. Iklan animasi Gojek versi Pevita Pearce dan Joe Taslim tidak hanya berfokus pada hal tersebut tetapi juga ada adegan action yang menarik ditambah dengan pengaplikasian video animasi yang menarik. Penyampaian pesan dan makna juga disampaikan melalui pernyataan Pevita Pearce kepada Joe Taslim "Harus Banget Nunggu Iklan" saat mendengarkan musik di YouTube dan ada iklan yang muncul sehingga Pevita membeli paket YouTube premium.

Dalam iklan ini juga sangat jelas pesan untuk menggunakan Gopay dengan sekali klik untuk transaksi apapun di GooglePlay. Pernyataan ini dikaitkan dengan teori dari Stuart Hall yang menjelaskan bagaimana sebuah proses dalam komunikasi yaitu saat pesan yang diciptakan menggunakan kode-kode tertentu disebut dengan Encoding.

Stuart Hall yang menjelaskan Decoding adalah penguraian kode yang dimaknai untuk menjadi sebuah pesan, informan dalam penelitian ini menerima pesan yang disampaikan oleh pihak Gojek melalui video iklan animasi dengan apa yang dapat dicerna dan dipahami informan mengenai pesan yang disampaikan. Berikut pemaknaan informan mengenai iklan Gojek.

1. Informan A, Kadek Yoga 22 tahun (mahasiswa)

Kadek Yoga berpendapat bahwa dari iklan animasi Gojek versi Pevita Pearce dan Joe Taslim, teknik amimasi yang digunakan sangat optimal menjadikan sebuah iklan terlihat sangat luar biasa,dan iklan dikemas dengan unik. Mengenai penggunaan Gopay dalam iklan untuk pembayaran YouTube premium memperlihatkan mudahnya penggunaan Gopay dalam bertransaksi, urusan pembayaran menggunakan transaksi Gopay sangat mudah, efektif, efesien bahkan sama sekali tidak pernah mengalami kesulitan. Dalam Iklan, Gojek juga menunjukkan bahwa Gojek selalu ada dalam keadaan apapun dan menggunakan teknik adegan action dalam iklan merupakan strategi marketing yang baik.

2. Informan B, Debora Lois 21 tahun (Mahasiswi)

Debora Lois berpendapat bahwa dari iklan animasi Gojek versi Pevita Pearce dan Joe Taslim, teknik animasi yang digunakan dalam iklan Gojek secara keseluruhan sangat bagus, grafisnya sangat professional, moving dan gerakan video sangat mulus bahkan animasnya dapat disetarakan dengan game Mobile Legend dan Pubg. Mengenai penggunaan Gopay dalam pembelian Youtube premium merupakan inovasi yang sangat luas biasa dan tidak akan terpikirkan oleh orang biasa. Saat bertransaksi menggunakan Gopay juga ada keuntungan yang ditawarkan yaitu cashback dan tidak ribet dalam urusan uang kembalian. Dalam iklan, pesan yang ingin disampaikan oleh Gojek yaitu Gojek 
bersedia untuk membantu masyarakat dengan layanan yang disediakan Gojek dan Gojek berusaha melayani customer dengan cepat. Dalam pengaplikasian adegan action dalam iklan menunjukkan bahwa Gojek dapat beradaptasi dengan apa yang sedang digemari masyarakat.

\section{Informan C, Dinoval Mustafa 25 tahun (Pegawai Negeri)}

Dinoval Mustafa berpendapat bahwa, teknik animasi yang digunakan dalam iklan Gojek iklan animasi Gojek versi Pevita Pearce dan Joe Taslim sangat menarik, trendi, kekinian dan modern. Bahkan terlihat sangat nyata. Video iklan animasi Gojek dapat menjadi contoh untuk anak muda dan animator sehingga dapat membuat video animasi yang lebih baik lagi dan pengaplikasian adegan action kedalam sebuah iklan menunjukkan bahwa Gojek sangat inovatif.

Mengenai penggunaan Gopay untuk pembayaran YouTube premium sangat bagus. Ini memperlihatkan secara jelas memperkenalkan sistem pembayaran menggunakan Gopay. Dalam iklan ini Gojek menunjukkan, bahwa pengguna dapat mengandalkan Gojek dalam situasi apa pun.

\section{Resepsi dan Pemaknaan Khalayak}

Berdasarkan dari keseluruhan hasil wawancara terhadap 3 (tiga) orang informan yang berbeda usia, pendidikan, latar belakang, dan lingkungan berbeda, dapat dilihat bahwa terdapat 1 (satu) kategori yang muncul dari khalayak yaitu kategori Dominant Hegemonic yang artinya posisi dimana media menyampaikan pesan, dan khalayak menerimanya. Pesan tersebut secara kebetulan juga disukai oleh khalayak.

Tidak ada informan dalam kategori Negotiated yaitu informan menyetujui apa yang disajikan oleh Iklan animasi Gojek dan menolak hal-hal yang tidak sesuai dengan apa yang mereka pikirkan atau dimana khalayak bersedia menerima ideologi dominan yang bersifat umum, namun mereka akan melakukan beberapa pengecualian dalam penerapannya.

Dalam penelitian ini juga tidak ada informan dalam kategori Oppositional yaitu menolak sepenuhnya dan tidak setuju dengan apa yang disampaikan dalam iklan animasi Gojek. Pernyataan ini dikaitkan dengan teori dari Stuart Hall (Morissan, 2014:4) yang mengidentifikasi tiga kategorisasi audiens yang telah mengalami proses encodeldecode sebuah pesan: Posisi Hegemoni Dominan (dominant hegemonic position). Posisi dominan dalam penelitian ini yaitu penerimaan khalayak terhadap pesan dianggap sesuai dengan makna pesan tanpa pengecualian. Dengan kata lain, khalayak sejalan dengan pemikiran atau kode yang dibangun oleh pengirim pesan dari awal sampai akhir video iklan yang disampaikan oleh Gojek.

Informan yang masuk dalam kategori Dominant Hegemonic terdiri dari 3 (tiga) orang informan yang rentang usia 21-25 tahun. Ketiga informan dalam kategori Dominant Hegemonic secara sepakat memiliki pendapat bahwa teknik animasi dalam iklan yang digunakan Gojek sangat bagus, menarik dan unik karena pengaplikasian animasi pada video sangat optimal. Penggunaan Gopay yang ditunjukkan pada iklan memperlihatkan mudahnya bertransaksi menggunakan Gopay.

Mengenai pelayanan Gojek, iklan dalam penelitian ini dapat dikatakan memperlihatkannya dengan sangat baik. Dalam iklan ini digambarkan Gojek mampu memberikan layanan tanpa batas meskipun dalam situasi sulit. Pengaplikasian adegan action dalam iklan adalah strategi marketing yang tepat, inovatif. Di sini Gojek dapat 
beradaptasi dengan perkembangan di masyarakat. Pernyataan ini dikaitkan dengan teori dari Stuart Hall (Morissan, 2014:4) mengenai salah satu kategorisasi audiens yang telah mengalami proses encodeldecode sebuah pesan yaitu posisi Dominant Hegemonic.

\section{Pemaknaan}

Pemaknaan informan terhadap pesan yang disampaikan iklan animasi Gojek cukup baik. Dalam penelitian ini informan memberikan interpretasi dengan cara yang berbeda tetapi punya memiliki makna yang serupa, hal ini karena dipengaruhi media, gender, umur, pekerjaan, pengalaman, keyakinan dan kemampuan mereka menerima pesan. Pernyataan ini dikaitkan dengan bagaimana peran khalayak dalam penerimaan pesan serta hubungan pandangan akan produsen dan konsumen terhadap sebuah teks (Rahmana, 2011).

Berdasarkan hasil wawancara dan analisis, terlihat pemaknaan khalayak terhadap iklan animasi Gojek menunjukkan persepsi positif terhadap Gojek. Persepsi Gojek membuat aktifitas khalayak menjadi lebih mudah. Gojek membawa perubahan dan pergeseran besar dalam kehidupan, dengan layanan yang serba cepat dan serba mudah menjadikan Gojek menjadi pilihan yang tepat bagi semua pengguna aplikasinya.

Hasil wawancara dan analisis memperlihatkan masyarakat saat membutuhkan layanan instan termasuk layanan Gojek. Penyebabnya adalah aktivitas masyarakat yang sangat bergantung pada layanan tersebut. Sebagai masyarakat modern, masyarakat harus dapat mengikuti semua perkembangan teknologi agar dapat memberikan keuntungan tersendiri, dompet digital Gopay.

\section{Simpulan}

Berdasarkan hasil penelitian yang dilakukan, dapat disimpulkan bahwa dalam sebuah pesan iklan, dapat menimbulkan berbagai resepsi dari khalayak tetapi memiliki makna yang serupa, dalam hal ini Dominant Hegemonic. Posisi dominan dalam penelitian ini yaitu penempatan khalayak terhadap penerimaan pesan sesuai dengan makna pesan yang diterima tanpa pengecualian.

Dengan kata lain, khalayak sejalan dengan pemikiran atau kode yang dibangun oleh pengirim pesan dari awal sampai akhir video iklan yang disampaikan oleh Gojek. Hal ini dimungkinkan terjadi karena pesan yang disampaikan iklan animasi Gojek tersampaikan dengan jelas bahkan khalayak memiliki resepsi positif terhadap layanan Gojek.

Melalui penelitian ini, peneliti juga menemukan bahwa iklan animasi Gojek versi Pevita Pearce dan Joe menunjukkan hal baru dalam sebuah iklan. Video iklan yang dibuat Gojek dikemas dengan unik menggunakan teknik animasi yang sangat optimal, grafisnya cukup professional. Gerakannya benar-benar sempurna.

\section{Ucapan Terima Kasih}

Peneliti ingin mengucapkan terima kasih kepada Fakultas Ilmu Komunikasi Universitas Tarumanagara, narasumber, serta semua pihak yang turut membantu peneliti sehingga penelitian ini dapat diselesaikan. 
Niluh Putu Krisna Utami, Septia Winduwati: Pemaknaan Khalayak pada Iklan Animasi Gojek Versi

Pevita Pearce dan Joe Taslim

\section{Daftar Pustaka}

Darmawan. (2012). Aspek Naratif Dalam Film Animasi Berbasis Format Video $360^{\circ}$ Dan Non-360 ${ }^{\circ}$. Jurnal Komunikasi Visual Wimba Hal. 19.

Hidayatullah dkk, (2011:63), Munir (2013:340), Vaughan dalam Binanto (2010:219), Munir (2013:327), Teori animasi dan konsep dasar animasi, file:///C:/Users/User/Downloads/file_10-BAB-II-landasan-teori.pdf (Diakses 11 Oktober 2020).

Ida, Rachmah. (2014). Metode Penelitian Studi Media dan Kajian Budaya. Jakarta: Prenada Media Group.

Mustafa, dkk. 2015. Membongkar makna dalam iklan "Greeting Airasia Belasungkawa”. Jakarta: Kompas Gramedia. Jurnal Sosioteknologi. Vol. 14, No. 3.

Pratiwi, Arisna, 2016, "Peran Brand Awareness Memediasi Daya Tarik Iklan Terhadap Brand Attitude Indomie Di Kota Denpasar". Skripsi. FE Dan Bisnis, Universitas Udayana.

Rahmana, Saleh (2011). Budaya, Media, Bahasa: Teks Utama Rancangan Cultural Studies. Yogyakarta: Jalasutra.

Rudi Aziz dan Asrul, Pengantar Sistem dan Perencanaan Transportasi, (Yogyakarta: Deepublish, 2014), hlm. 1.

Stuart Hall (dalam Morissan, 2014:550-551). Pemaknaan Khalayak Terhadap Informasi Kasus Penodaan Agama Oleh Basuki Tjahaja Purnama Di Media Sosial Youtube. Departemen Ilmu Komunikasi Fakultas Ilmu Sosial dan Ilmu Politik Universitas Diponegoro. 